\title{
A PARTICIPAÇÃO COMUNITÁRIA EM PROJETOS DE SOLUÇÕES BASEADAS NA NATUREZA NA CIDADE DE SÃO PAULO ESTUDO DAS HORTAS URBANAS, HORTA DA DONA SEBASTIANA, AGROFAVELA-REFAZENDA E HORTA POPULAR CRIANDO ESPERANÇA
}

Babette Fernandes Martins da Costa

Tatiana Sakurai

\section{RESUMO}

As hortas urbanas integram a categoria de Soluções Baseadas na Natureza $(\mathrm{SbN})$ capazes de proporcionar benefícios tanto ambientais quanto sociais; entre estas, podemos citar a regulação de microclimas urbanos, o suporte à diversidade e segurança alimentar, o incentivo à educação ambiental e a resiliência de comunidades. $\mathrm{O}$ artigo tem como objetivo investigar se projetos dessa natureza, quando criados e geridos sob a iniciativa de comunidades, organizações de bairro e outros grupos sociais possuem maior eficiência, engajamento e continuidade em comparação a projetos de iniciativa privada e/ou pública, sem participação social em sua criação e desenvolvimento. Por meio de estudos de casos múltiplo, ao lado de entrevistas semi-estruturadas com lideranças, visitas de campo e pesquisa bibliográfica, foram selecionadas três hortas urbanas em contextos periféricos na cidade de São Paulo: a Horta da Dona Sebastiana, membro da Associação de Agricultores da Zona Leste e auxiliada por uma Organização Não Governamental; a AgroFavela-Refazenda, localizada em Paraisópolis, patrocinada por uma empresa multinacional; e a Horta Popular Criando Esperança, na Vila Nova Esperança, autônoma.

O trabalho também discute o conceito de Justiça Ambiental como um interessante instrumento de análise, em uma cidade socialmente e ambientalmente desigual como São Paulo - na qual os riscos ambientais 
e a falta de investimento atingem desproporcionalmente populações mais pobres e vulneráveis. Como resultado, concluiu-se que projetos como as hortas urbanas podem ser ferramentas potenciais de redução de desigualdades ambientais e, quando com a participação de comunidades, também transformadores sociais. Ressalta-se a importância da implementação de $\mathrm{SbNs}$ em áreas periféricas, as quais sofrem mais injustiças ambientais e necessitam mais destas infraestruturas do que nas áreas nobres de São Paulo - onde muitas SBNs são atualmente construídas e amplamente divulgadas.

\section{Palavras-chave}

Soluções baseadas na Natureza (SbN); Justiça Ambiental. Resiliência; Hortas Urbanas; Comunidades. 


\section{LA PARTICIPACIÓN COMUNITARIA}

EN PROYECTOS DE SOLUCIONES

BASADAS EN LA NATURALEZA EN

LA CIUDAD DE SÃO PAULO

ESTUDIO DE LAS HUERTAS

URBANAS, HUERTA DE DONA

SEBASTIANA, AGROFAVELA-

REFAZENDA Y HUERTA POPULAR

CRIANDO ESPERANÇA

Babette Fernandes Martins da Costa

Tatiana Sakurai

\section{RESUMEN}

Las huertas urbanas son una categoria de Soluciones Basadas en la Naturaleza (SbN) capaces de proporcionar beneficios tanto ambientales como sociales; como por ejemplo, la regulación de microclimas urbanos, el soporte a la diversidad y la seguridad alimentaria, el incentivo a la educación ambiental y la resiliencia de comunidades. El artículo tiene como objetivo investigar si los proyectos de esta naturaleza creados y generados bajo la iniciativa de comunidades, organizaciones de barrio y otros grupos sociales poseen mayor eficiencia, compromiso y continuidad en comparación con proyectos de iniciativa privada y/o pública, sin participación social en su creación y desarrollo. A través de estudios de casos múltiples y de la combinación de entrevistas semi estructuradas a lideres, visitas de campo e investigación bibliográfica, fueron seleccionadas tres huertas urbanas en contextos periféricos en São Paulo: la Huerta de Dona Sebastiana, miembro de la Asociación de Agricultores de la Zona Este y auxiliada por una Organización No Gubernamental; la AgroFavela-Refazenda, localizada en Paraisópolis, patrocinada por una empresa multinacional; y la Huerta Popular Criando Esperança, autónoma.

En el trabajo, se discute también el concepto de Justicia Ambiental como un instrumento de análisis interesante en una ciudad social y 
ambientalmente desigual como São Paulo, en la cual los riesgos ambientales y la falta de inversión alcanza de manera desproporcionada a las poblaciones más pobres y vulnerables. Como resultado, se concluye que proyectos como las huertas urbanas pueden ser herramientas potenciales de reducción de desigualdades ambientales y, cuando son ejecutadas con la participación de comunidades, también se convierten en transformadores sociales. Se destaca la importancia de la implementación de SbNs en áreas periféricas que sufren injusticias ambientales y que necesitan de estas infraestructuras más que en las áreas nobles de São Paulo, donde muchas SbNs son actualmente construidas y ampliamente divulgadas.

\section{Palabras-clave}

Soluciones Basadas en la Naturaleza (SbN); Justicia Ambiental; Resiliencia; Huertas Urbanas; Comunidades. 


\title{
COMMUNITY PARTICIPATION IN
}

PROJECTS WITH NATURE-BASED

SOLUTIONS IN THE CITY OF SÃO

PAULO

\author{
A STUDY OF URBAN GARDENS, \\ HORTA DA DONA SEBASTIANA, \\ AGROFAVELA-REFAZENDA AND \\ HORTA POPULAR CRIANDO \\ ESPERANÇA
}

Babette Fernandes Martins da Costa

Tatiana Sakurai

\begin{abstract}
Urban gardens belong to the category of Nature-Based Solutions (NbS), capable of providing both environmental and social benefits; among these, we can mention the regulation of urban microclimates, support for diversity and food security, encouragement of environmental education, and community resilience. The article aims to investigate whether projects of this nature, when created and managed under the initiative of communities, neighborhood organizations and other social groups, have greater efficiency, engagement and continuity in comparison to private and/or public initiative projects, without social participation in their creation and development. Through multiple case studies, alongside semi-structured interviews with leaders, field visits and bibliographic research, three urban gardens were selected in peripheral contexts in the city of São Paulo: Horta da Dona Sebastiana, a member of the Association of Farmers from Zona Leste (East Side of São Paulo), and supported by a Non-Governmental Organization; the AgroFavela-Refazenda, located in Paraisópolis, sponsored by a multinational company; and Horta Popular Criando Esperança ("Popular Garden Creating Hope"), an autonomous one.
\end{abstract}

The work also discusses the concept of Environmental Justice as an interesting tool for analysis, in a socially and environmentally unequal 
city like São Paulo - in which environmental risks and lack of investment disproportionately affect the poorest and most vulnerable populations. As a result, it concludes that projects such as urban gardens could be potential tools for reducing environmental inequalities and, when with the participation of communities, they act as social transformers. We emphasize the importance of implementing NbS in peripheral areas, which suffer more environmental injustices and need these infrastructures more than the prime areas of São Paulo - where many NbS already exist, widely known and publicized.

\section{Keywords}

Nature-based Solutions (NbS); Environmental Justice; Resilience; Urban Gardens; Communities. 


\section{INTRODUÇÃO}

\section{Hortas Urbanas e Soluções baseadas na Natureza}

Diante da crise socioeconômica, ambiental e política que vivemos no Brasil e considerando que aproximadamente $85 \%$ de sua população vive em áreas urbanas (IBGE, 2017), evidencia-se a urgência e a necessidade de novas alternativas para pensar a produção do espaço urbano de maneira democrática, não-excludente e ambientalmente justa. Tendo em vista que no país $85 \%$ das cidades são construídas sem o envolvimento de arquitetos(as) e engenheiros(as) (CAU/BR; Instituto Datafolha, 2015), seria possível (re)pensar as cidades e seus espaços coletivos a partir e com o (re)conhecimento do saber tácito de comunidades urbanas?

Apesar de recentes, especialmente no Brasil (Rodrigues et al., 2021; Fraga \& Sayago, 2020; Stöberl et. al. 2019) estudos apontam que as Soluções baseadas na Natureza ( $\mathrm{SbN}$ ) podem ser uma ferramenta importante para a proposição e desenvolvimento de um urbanismo mais resiliente e adaptável. As SbNs são um conceito guarda-chuva que abarca diferentes tecnologias ou intervenções territoriais que visam melhorar a qualidade urbana através da natureza (IUCN, 2020; LSBN, 2021). Essas intervenções procuram solucionar problemas urbanos e mitigar questões relacionadas ao meio ambiente, por exemplo ilhas de calor, enchentes e deslizamentos.

De acordo com Cohen-Shacham et al. (2016) as SbN devem seguir as normas e princípios de conservação da natureza, manter a diversidade biológica e cultural do ambiente e podem ser aplicadas em diversas escalas de atuação. Entre exemplos de SbNs, encontram-se jardins de chuva e outros sistemas sustentáveis de drenagem urbana, telhados e paredes verdes, parques e hortas urbanas. No entanto, áreas e infraestruturas verdes não necessariamente classificam-se como SbNs; apenas quando procuram solucionar problemas de ordem ambiental de maneira ecológica, partindo dos princípios de conservação da natureza.

Neste artigo, comparou-se experiências em São Paulo acerca da relação entre três comunidades com uma categoria de Solução Baseada na Natureza em específico, as hortas urbanas. Partiu-se da hipótese que hortas urbanas são $\mathrm{SbNs}$ que podem trazer resultados positivos ambientais e sociais e que são mais eficazes e duradouras em suas propostas quando pensados de maneira participativa em conjunto com a população local, e não impostas por empresas ou pelo setor público sem diálogo e envolvimento comunitário.

Segundo Artmann e Sartison (2018), práticas de agricultura urbana e peri-urbana podem ser consideradas SbNs por serem uma solução híbrida para o desenvolvimento urbano sustentável, combinando 
aspectos naturais com o meio construído em áreas urbanas. Do ponto de vista ambiental, estes autores também destacam, segundo experiências do norte global, que hortas urbanas podem contribuir para a regulação de microclimas, da qualidade do ar e do solo, polinização e redução de ruídos urbanos. Estudos empíricos demonstram como a agricultura urbana pode ser uma maneira importante de reduzir gases do efeito estufa como o $\mathrm{CO}_{2}$, reduzindo o transporte de alimentos para centros urbanos. Além da perspectiva ambiental, foi constatado por diversos estudos mapeados por esses mesmos autores que hortas urbanas garantem saúde, segurança alimentar, educação ambiental, contato com a natureza em meio urbano, melhoria da saúde mental, engajamento civil e por vezes geração de renda para a população em seu redor.

Hortas urbanas podem também contribuir para a requalificação de espaços, tendo em vista que por vezes são construídas em terrenos abandonados utilizados para descartes irregulares, ou aproveitando áreas subutilizadas das cidades, como visto adiante nos estudos de casos deste trabalho. Esta categoria de intervenção também pode ser sinônimo de mecanismo de transformação social, na medida em que traz benefícios na esfera da igualdade de gênero, contribui para a promoção de cidadania ambiental, do fortalecimento comunitário e da expressão política de comunidades, com a conexão com a ancestralidade e com o planejamento territorial (Biazoti, 2020, p. 34).

Biazoti (2020, p. 14) destaca que a agricultura urbana não é novidade no território paulistano, embora tenha crescido consideravelmente a partir da década de 2010, através de diversos grupos de ativismo socioambiental, e com a reinserção do território rural no Plano Diretor Estratégico do município (PDE) de 2014. No entanto, a respeito das hortas comunitárias, observa-se que este tipo de iniciativa obteve grande visibilidade em matérias jornalísticas e presença em redes sociais, principalmente em bairros de classe média alta da zona oeste e central da cidade, como por exemplo a Horta das Corujas, na Vila Madalena; a Horta City Lapa, no Alto da Lapa, e a Horta dos Ciclistas, na Av. Paulista.

\section{Hortas Urbanas e Justiça Ambiental}

Partindo do pressuposto de que a degradação ambiental, suas consequências e mitigações não são democráticas, optou-se utilizar, ao estudar a inserção de Soluções baseadas na Natureza em territórios em disputa política, ambiental e social o conceito de Justiça Ambiental. Neste artigo será utilizada a visão mais ampla deste conceito - de acordo com a United States Environmental Protection Agency:

A justiça ambiental é o tratamento justo e o envolvimento significativo de todas as pessoas, independentemente 
de raça, cor, nacionalidade ou renda, com relação ao desenvolvimento, implementação e cumprimento de leis, regulamentos e políticas ambientais. Esta meta será alcançada quando todos desfrutarem: o mesmo grau de proteção contra os riscos ambientais e de saúde, e igual acesso ao processo de tomada de decisão para ter um ambiente saudável para viver, aprender e trabalhar. ${ }^{1}$

O termo Justiça Ambiental surgiu na década de 1980 nos Estados Unidos, em um contexto de preocupações ambientais e de cunho técnico e político, combinado com protestos e movimentos sociais importantes, como o Movimento dos Direitos Civis. O Movimento por Justiça Ambiental e contra o Racismo Ambiental ${ }^{2}$ foi catalisado através da denúncia de minorias étnicas, raciais e geralmente de baixa renda em episódios de distribuição injusta dos impactos ambientais.

Em São Paulo, a (in)justiça ambiental está atrelada à distribuição desigual de locais como áreas de risco ou contaminadas, por exemplo, onde a degradação ambiental combina-se com a desigualdade social, agravando a vulnerabilidade da população mais pobre. De acordo com um exercício realizado por Acselrad, Mello e Bezerra (2009) existe uma relação direta na cidade entre distritos dotados de alto Índice de Exclusão Social (IES) e áreas com risco de acidentes em encostas.

1. Tradução das autoras:

"Environmental justice is the fair treatment and meaningful involvement of all people regardless of race, color, national origin, or income, with respect to the development, implementation,

and enforcement of environmental laws, regulations, and policies. This goal will be achieved when everyone enjoys:

the same degree of protection from environmental and health hazards, and

equal access to the decision-making process to have a healthy environment

in which to live, learn, and work".

2. Definido por Bullard (2005)

como: "qualquer política, prática ou diretiva que afete ou prejudique, de formas diferentes, voluntária ou involuntariamente, a pessoas, grupos ou comunidades por motivos de raça

ou cor. Esta ideia se associa com políticas públicas e práticas industriais encaminhadas a favorecer as empresas impondo altos custos às pessoas de cor. As instituições governamentais,

jurídicas, econômicas, políticas e militares reforçam o racismo ambiental e influem na utilização local da terra, na aplicação de normas ambientais no estabelecimento de instalações industriais e, de forma particular, os lugares onde moram, trabalham e têm o seu lazer as pessoas de cor".
Rodrigues (2020), confirma que a desigualdade no acesso e no direito à cidade se sobrepõem à exposição aos riscos e às vulnerabilidades ambientais, sendo as áreas disponíveis encostas de morros, margens de rios, terrenos contaminados ou áreas de proteção de mananciais.

Essa lógica perversa de ocupação urbana, alimentada pelo Estado, que (des)valoriza o espaço ao regulamentar o uso e ocupação do solo, acaba por contribuir para as (in)justiças ambientais através de dinâmicas político-econômicas, associando os riscos ambientais às populações periféricas (Maricato, 2015). Rodrigues (2020), a partir da relação de "vulnerabilização de vidas humanas" e território apontada por Oliveira (2018) ressalta que,

\footnotetext{
...para analisar as injustiças ambientais no Brasil, é preciso olhar tanto para o modelo econômico capitalista, que concentra riqueza e reproduz desigualdades socioambientais, como para o processo de colonização que tem delimitado as diversas formas de exclusão social na história da sociedade brasileira. (p. 186)
}

Neste contexto de (in)justiça ambiental e desigualdade social, hortas urbanas podem ser projetos que vão contra esta lógica hegemônica, tornando comunidades ambientalmente mais justas e sendo vetores de transformação urbana e social, como evidenciado nos casos relatados posteriormente. Porém, ressalta-se que o termo horta urbana engloba diversos tipos de práticas e cultivos que diferem-se em suas propostas, atores, e sua localidade. É importante reconhecer que nem toda experiência de horta urbana é comunitária, orgânica ou 
segue princípios agroecológicos (Biazoti, 2020, p. 43), podendo ser por exemplo, uma horta institucional, de uma empresa ou em propriedade particular, seguindo diversos métodos de plantio e organização.

A agricultura urbana distingue-se da agricultura rural devido à sua proximidade ao mercado de consumo, com a economia e mundo urbano, o que muitas vezes faz com que ocorra um vazio institucional, devido à falta de políticas públicas para tal meio (Biazoti, 2020, p. 35). Estas experiências, no caso brasileiro, podem ocorrer de forma regular ou não, em áreas na cidade impossibilitadas para outros usos, como por exemplo sob linhas de transmissão de energia, em praças, lajes ou terrenos baldios. São comuns casos de famílias que produzem há anos nas bordas da cidade e foram englobadas pelo processo de urbanização. Estas áreas geridas de forma comunitária ou familiar, muitas vezes com zoneamento específico na legislação municipal e que podem ter apoio governamental para assistência técnica e fornecimento de insumos (Biazoti, 2020, p. 38).

Comunidades, grupos raciais e bairros são os principais atores do movimento por justiça ambiental desde o começo da luta, nos Estados Unidos. Laituri e Kirby (1994, p. 15, citado por Acserald, Mello, \& Bezerra, 2009, p. 19) retomam uma pesquisa realizada em 1987 por Robert D. Bullard que apontou que "a composição racial de uma comunidade é a variável mais apta a explicar a existência ou inexistência de depósitos de rejeitos perigosos de origem comercial em uma área". O Brasil apresenta tendências similares pois em todas as grandes regiões do país a porcentagem de população branca com acesso à água canalizada, e à esgoto e fossa séptica é consideravelmente maior do que a porcentagem da população negra e parda (IBGE, 2000).

A relevância destes grupos é importante não somente na mobilização por justiça ambiental e direitos humanos, contribuindo também para os estudos de risco através do saber experiencial: a população local é geralmente a primeira a detectar os indícios de algum problema ou desequilíbrio ambiental através de cheiros, percepção visual, apreensão de doenças, etc (Corburn, 2007; Rodrigues, 2020).

Acerca da injustiça ambiental no meio urbano, ressalta-se a relação entre os movimentos por moradia e comunidades envolvidas com a pauta ambientalista:

... as lutas dos chamados movimentos de moradia têm clara relação com a solução das questões ambientais. Se em algumas circunstâncias eles induzem a invasão de áreas de proteção ambiental, produzindo conflitos importantes com o chamado movimento ambientalista, cabe reconhecer a proximidade entre essas duas lutas, sobretudo entendendo que os mais pobres - na grande maioria dos casos - são os mais ameaçados pelas condições ambientais existentes. (Acselrad, Mello, \& Bezerra, 2009, p. 68). 
Nos estudos de casos apresentados, observa-se além das comunidades outros atores presentes nos territórios, como empresas através de patrocínios e concessões, parcerias e auxílios de Organizações Não Governamentais, e o Estado através de incentivos, editais, legislação fundiária e planejamento urbano.

Na inserção de Soluções baseadas na Natureza em territórios populares, entende-se o projeto participativo como ferramenta fundamental para seu êxito e manutenção. Segundo Noia (2017), no campo da arquitetura e do urbanismo,

O projeto participativo pode ser definido como um processo de capacitação e empoderamento, sendo seu produto, a arquitetura comunitária, um processo contínuo de aprendizado e desenvolvimento. Sua prática cria um reforço natural à comunidade, trazendo consigo a identidade de grupo e a noção associativa. (p.107)

As práticas participativas se baseiam no preceito de que um ambiente funciona melhor quando os moradores da região participam de sua criação e gestão (Noia, 2017, p. 107), influenciando positivamente a criação de espaços comunitários. O projeto participativo visa a emancipação social e maior capacidade de ação no ambiente através da troca de experiências e aprendizados entre os envolvidos, visando uma apropriação do conhecimento para sua replicabilidade em situações posteriores. Nesse sentido, analisam-se os três projetos selecionados tendo em vista a participação ativa de comunidades como algo central na implementação de Soluções baseadas na Natureza que combatam (in)justiças ambientais de modo emancipatório e bem sucedido.

3. MARTINS DA COSTA, B. F. (2021). EJ-Sul: Projetos de Justiça Ambiental na América Latina. (Relatório Final de Iniciação Científica). Universidade de São Paulo, São Paulo, SP, Brasil. Com o apoio do Programa Unificado de Bolsas de Estudo para Apoio e Formação de Estudantes de Graduação - PUB-USP, Edição 2020/2021. SAKURAI, T. (2019). Diálogos NorteSul: projetos e Justiça Ambiental nas cidades de São Paulo e Los Angeles (Projeto de pesquisa). Universidade de São Paulo, São Paulo, SP, Brasil. A primeira fase foi subsidiada pelo EDITAL N. 09/2019 - Print USP/ CAPES

\section{MATERIAIS E MÉTODOS}

Este trabalho situa-se primordialmente na grande área de Ciências Sociais Aplicadas (Arquitetura e Urbanismo) e caracteriza-se pela abordagem qualitativa. A fundamentação teórica, extração, manipulação e leitura de dados adotou ferramentas e por vezes métodos transpostos originários de outras disciplinas e áreas do conhecimento em uma relação interdisciplinar. Buscou-se um olhar dinâmico sobre a realidade social para a qual este trabalho se volta, para a compreensão do fenômeno proposto no território analisado, por meio da análise de seus diferentes contextos: social, econômico, ambiental e territorial. Adotou-se como método o Estudos de Casos múltiplo, conforme descrito por Martins (2008) a partir da leitura crítica de Yin (2001). A partir de um levantamento mais abrangente conduzido pelas autoras ${ }^{3}$, no qual foram mapeados e categorizados projetos em diversas escalas do urbano, as três hortas deste estudo foram selecionadas por estarem em áreas periféricas da cidade, mas em localizações geograficamente 
distintas, sendo elementos relevantes na paisagem, na história e na cultura do território onde se situam. Outro critério importante foi a identificação de diferentes atores participantes, o que possibilitou a análise comparativa dentro do recorte pretendido.

Destacam-se como fontes o material produzido pelas comunidades e atores pesquisados, tais como vídeos, sites, blogs e redes sociais, além de publicações e documentos disponibilizados por centros de pesquisa, institutos e pesquisadores. Foram realizadas visitas de campo presenciais documentadas fotograficamente, combinadas com entrevistas semiestruturadas com as lideranças, coordenadores ou participantes das hortas, agendadas previamente e respeitando os protocolos sanitários vigentes à época. As entrevistas foram conduzidas a partir de perguntas sobre a história, o funcionamento e gestão da horta, e em seguida sobre o trabalho e a participação de agentes que atuam no território e sua relação com outros atores. Optou-se neste artigo por manter os nomes pelos quais os entrevistados se auto-declararam.

\section{ESTUDOS DE CASOS: TRÊS HORTAS URBANAS EM REGIÕES PERIFÉRICAS DE SÃO PAULO}

A partir das questões apontadas anteriormente e os critérios citados acima, foram selecionadas as hortas urbanas em contexto periférico ${ }^{4}$ : a Horta da Dona Sebastiana, localizada em São Mateus na Zona Leste; a AgroFavela-Refazenda, de Paraisópolis, na Zona Sul e a Horta Popular Criando Esperança, na Vila Nova Esperança, Zona Oeste de São Paulo. Além dos grupos sociais diretamente envolvidos, foram identificados outros atores relevantes como o poder público, através do zoneamento e da regularização fundiária da terra; empresas, a partir de parcerias e patrocínios; e organizações não governamentais, no auxílio administrativo e apoio às hortas.

4. Neste artigo definiu-se como periferia os territórios em São Paulo caracterizados pela pobreza, precariedade e distância em relação ao centro. Este termo, até 1980 mais presente na academia, passou a ser apropriado e reivindicado a partir da década de 1990, passando por um processo histórico de modificação de seu significado, a partir de expressões culturais como o rap e o hip hop (D'Andrea, 2020).

\section{Horta da Dona Sebastiana. São Mateus, Zona Leste - SP}

A Horta da Dona Sebastiana, localiza-se sob uma linha de transmissão de energia em São Mateus, Zona Leste de São Paulo e caracteriza-se pela gestão familiar, com o auxílio de uma Organização Não Governamental (ONG) e membro de uma associação de agricultores. Esta horta é uma entre outras que compartilham um grande terreno cujos "lotes" foram divididos por famílias, e atualmente é gerida por Dona Sebastiana. Seu marido, Seu Genival, já falecido, foi um dos fundadores da Associação de Agricultores de São Mateus, hoje Associação de Agricultores da Zona Leste (AAZL), na qual atualmente estão cadastradas 14 hortas. Além do consumo próprio, D. Sebastiana comercializa seus produtos para moradores da vizinhança, através da venda em uma pequena loja no portão da horta. Sobre a decisão de escolha de plantio, o casal 

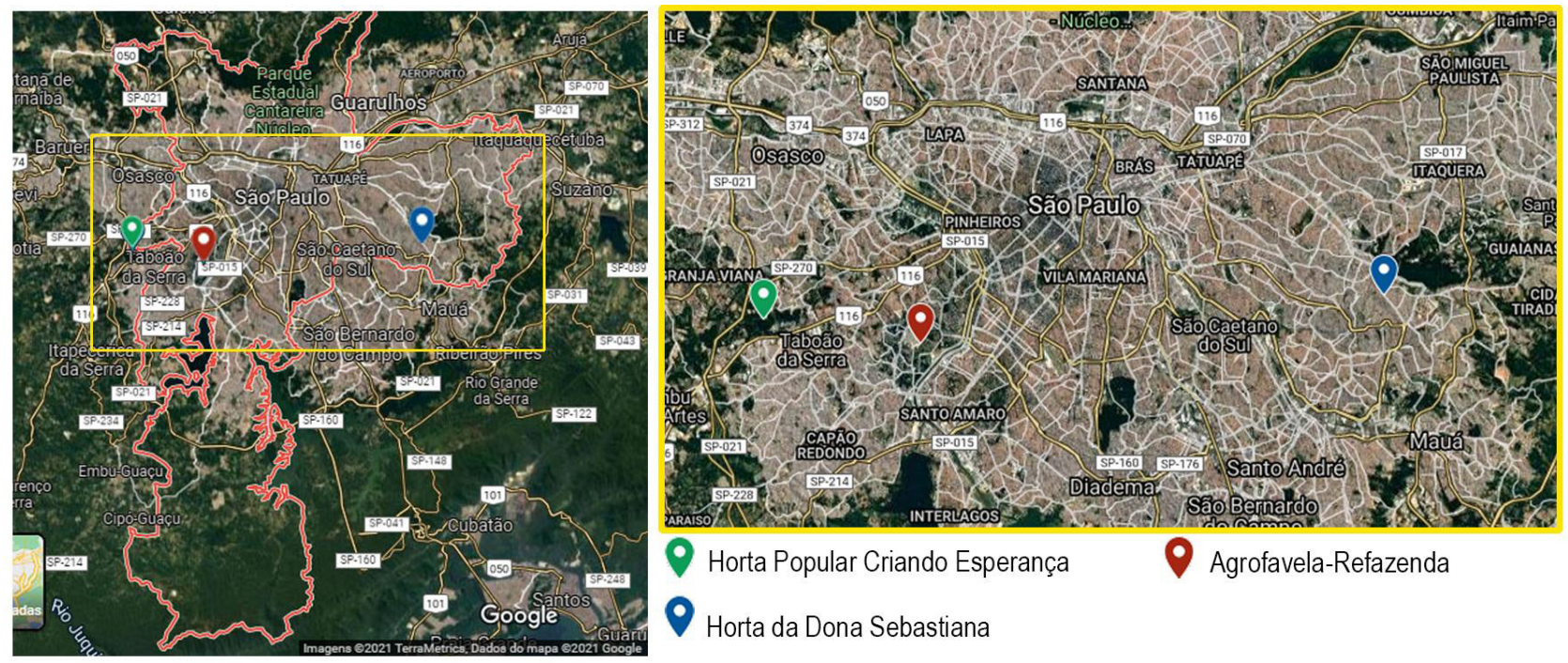

FIGURA 1. Localização das três hortas urbanas na cidade de São Paulo selecionadas. Fonte: Elaborado pelas autoras com base na plataforma GoogleMaps, 2021.

de agricultores decidiu, nas palavras de Sebastiana (2021), "plantar aquilo que a gente gosta de plantar, e o que o povo gosta". Na horta são cultivados principalmente temperos, hortaliças e alimentos cujo plantio é mais rápido, além de plantas medicinais. O terreno sob o linhão de transmissão de energia, na qual a horta ocupa um espaço de aproximadamente 8.000 metros quadrados, é de propriedade da Enel Brasil, que fiscaliza mensalmente o terreno e realiza um contrato de comodato com a duração de 5 anos, e que atualmente encontra-se em espera de renovação.

De acordo com o depoimento da agricultora concedido à Martins da Costa (2021) e com o site da AAZL (n.d.), a horta e a associação iniciaram através de atividades relacionadas à discussões acerca do Plano Diretor Municipal, em 2002. Uma bióloga, funcionária da Subprefeitura de São Mateus ao fazer um levantamento da região, destacou como a cultura rural estava presente na região, ao observar que diversas famílias plantavam em chácaras ou embaixo de linhões de energia. Levantaram também uma grande quantidade de nascentes preservadas em remanescentes de mata atlântica na região, compondo cinco sub-bacias hidrográficas formadoras da cabeceira do Rio Aricanduva. Identificando o potencial de geração de renda, desenvolvimento e preservação da natureza por meio da agricultura urbana, ela e outros funcionários da subprefeitura se engajaram para fomentar "a agricultura local como fator de desenvolvimento através da cessão de áreas públicas para plantio e orientação técnica aos agricultores" (AAZL, n.d.). Na mesma época discutia-se a Lei da Agricultura Urbana e Periurbana, que em 2004 fomentou o Programa de Agricultura Urbana e Periurbana do 


\title{
Município de São Paulo (PROAURP).
}

Com o apoio da Subprefeitura local, a associação obteve assessoria e capacitação para a produção sem o uso de aditivos químicos e a comercialização do excedente em feiras na cidade. Sobre as reuniões mensais com agricultores da associação e com profissionais da subprefeitura, Sebastiana (2021) comenta:

\begin{abstract}
...e aí a gente foi aprendendo com ela (funcionária da subprefeitura) o bem-estar de cuidar da terra, e aí entrou o meio ambiente no meio. A terra é chamada de mãe no nosso ponto de vista, e é verdade, que ela produz todos os nossos alimentos, e nós não devemos agredir a terra. Quando nós agredimos a terra, a gente tá fazendo mal pra nós mesmos, porque é onde nós conseguimos os nossos alimentos. E aqui em São Mateus tem bastante manancial de água, e olha que o bairro não é tão grande. E aí pronto, a gente começou a trabalhar em cima dessa ideologia, de defender mananciais de água, não colocar veneno na terra, e assim a gente começou a criar gosto. Hoje eu tenho isso como uma oração. E planto, colho, depois planto outro, mas não uso nada ofensivo à terra. Uso coisas naturais, se não der certo então corta e planta outro. É uma alternativa.
\end{abstract}

Sebastiana e seu marido, Genival, voltaram a plantar prestes a se aposentarem e relata que em sua juventude os dois chegaram a trabalhar na roça, sendo "agricultores de milho, feijão, mandioca", mas não sabiam trabalhar com hortaliças. Ela se mudou com vinte e dois anos para São Paulo em busca de emprego e trabalhou em indústrias durante anos, até entrarem em contato com funcionários da subprefeitura e começarem a plantar no terreno onde hoje é a horta. Acerca de sua origem e relação com o plantio, Sebastiana (2021) relata:

\footnotetext{
Eu me defino como agricultora, porque é da minha raiz que eu venho, é como se eu vivesse do meu tempo passado, de uma maneira mais melhor [sic] ainda, porque eu aprendi a cuidar da terra, porque lá na minha terra eu queimava as coisas, hoje não queimo e se eu for dar uma palestra pra uma pessoa eu falo que não queimo uma folha, uma palha, ela tem que ser jogada para constituir a terra, por que a queimagem faz muito mal. Além da atmosfera, ela perde todas as substâncias, e nós não sabia [sic] disso, pensava que dava adubo depois de queimar, e não é nada disso.
}

Além da AAZL, a horta da Dona Sebastiana já contou com o apoio da Cidades Sem Fome, que se define como "uma organização não governamental (ONG) que desenvolve projetos de agricultura sustentável em áreas urbanas e rurais, baseados nos princípios da produção orgânica" (Cidades Sem Fome, 2021). Em seu site a ONG não disponibiliza em quais hortas atua ou já atuou, porém menciona que foi a responsável pela fundação de 25 hortas em São Paulo. Notase nessa plataforma e em vídeos institucionais que a Horta da D. Sebastiana é considerada uma horta modelo pela ONG e pela Enel. 
Entretanto, segundo Sebastiana em seu depoimento, a parceria com a ONG não estava mais ativa naquele momento.

\section{AgroFavela-Refazenda. Paraisópolis, Zona Sul - SP}

FIGURA 2. Dona Sebastiana em sua horta. Fonte: Acervo das autoras, 2021.

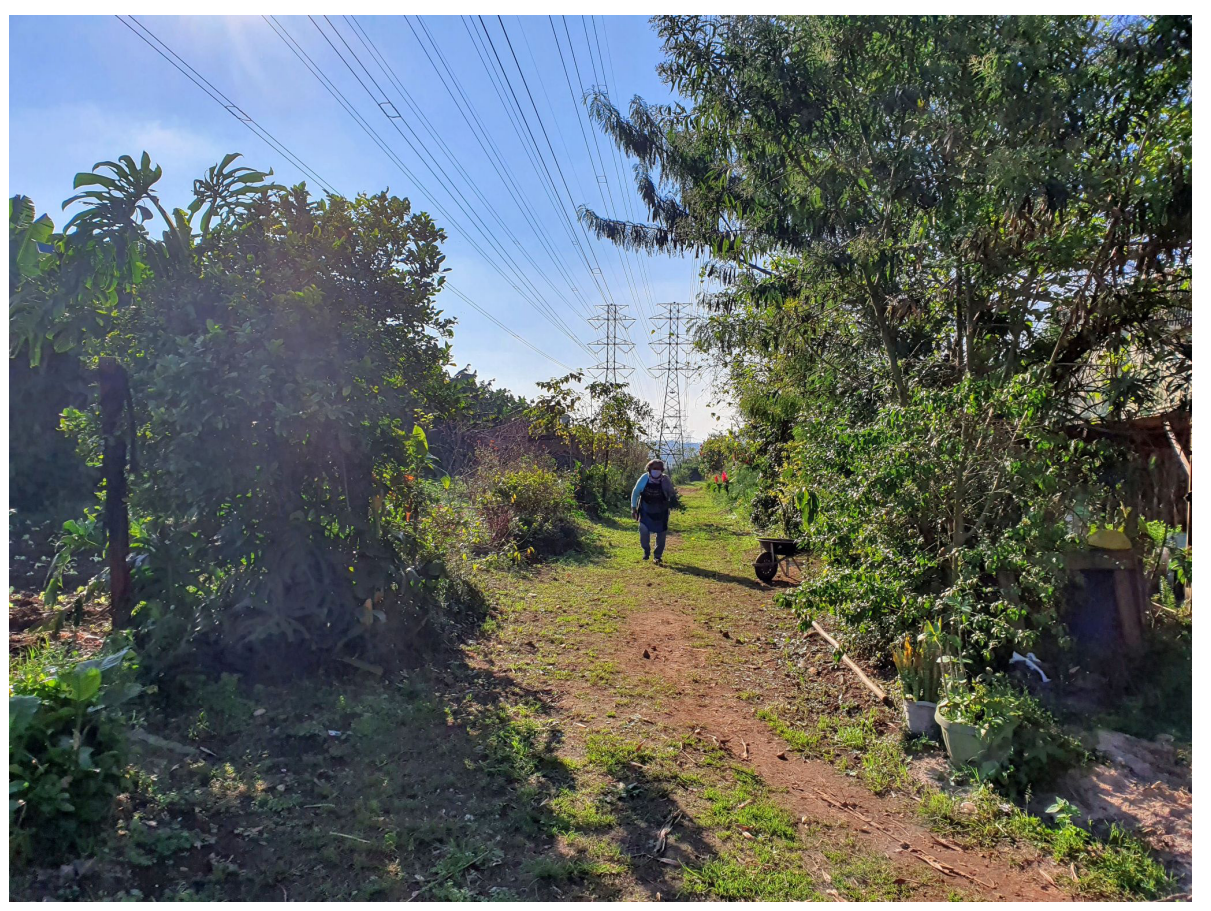

A AgroFavela-Refazenda, horta autodenominada comunitária, localizada na favela Paraisópolis no subdistrito Vila Andrade, foi selecionada para análise com o objetivo de entender as dinâmicas entre uma comunidade e parcerias externas diversas. É patrocinada por uma empresa multinacional, a Sodexo, por meio do Instituto Stop Hunger e tem o apoio de pessoas físicas, organizações e outras empresas, como por exemplo, a City Farm, um empreendimento que desenvolve protótipos para o plantio de hidropônicos em contextos urbanos. A horta foi idealizada e é administrada por lideranças de Paraisópolis, e foi instalada no antigo estacionamento do Pavilhão G10 Favelas, sendo o plantio não realizado direto na terra, como nos outros dois casos analisados. Ressalta-se que é a horta mais jovem estudada neste trabalho, inaugurada em outubro de 2020, e segundo a própria administração, ainda está na fase piloto.

O projeto tem como enfoque o cuidado com as mulheres da comunidade, em especial mães solos que se encontram em situação de vulnerabilidade social, e tem como objetivo incentivar com que elas aprendam e plantem em suas casas, especialmente nas lajes, por meio da doação de protótipos da City Farm, capaz de gerar um complemento de renda familiar com a venda do excedente. Apesar 
de se autodeclarar comunitária, a horta é cuidada atualmente por um grupo restrito de funcionários especializados. A participação das mulheres da comunidade ocorre por turnos através da colheita e por meio da recepção de doações de mudas e insumos, além de oficinas sobre plantio realizado pelos funcionários.

Em uma perspectiva ampliada, Renata (2021) funcionária, administradora auxiliar da horta, diz:

\begin{abstract}
...A importância delas (mulheres) é que a gente quer ver meio que o futuro, uma prosperidade em relação ao conhecimento, ao manuseio de plantas, e a importância delas é elas entrarem em contato com a natureza. A gente sabe que morar aqui não é fácil, ainda mais sendo mulher, é uma questão muito delicada, então acho que elas participando, tem a oportunidade de melhorar um pouquinho a questão da saúde mental e da alimentação.
\end{abstract}

Há algumas árvores frutíferas plantadas diretamente na terra, porém a maioria das plantas está distribuída em caixotes de plástico e nos protótipos de horta vertical, através de uma tecnologia de plantio de hidropônicos, desenvolvida pela empresa parceira. Não há composteira no local e o foco é no plantio de hortaliças mais convencionais, como espinafre, alface, almeirão, além de temperos, ervas medicinais e algumas PANCs.
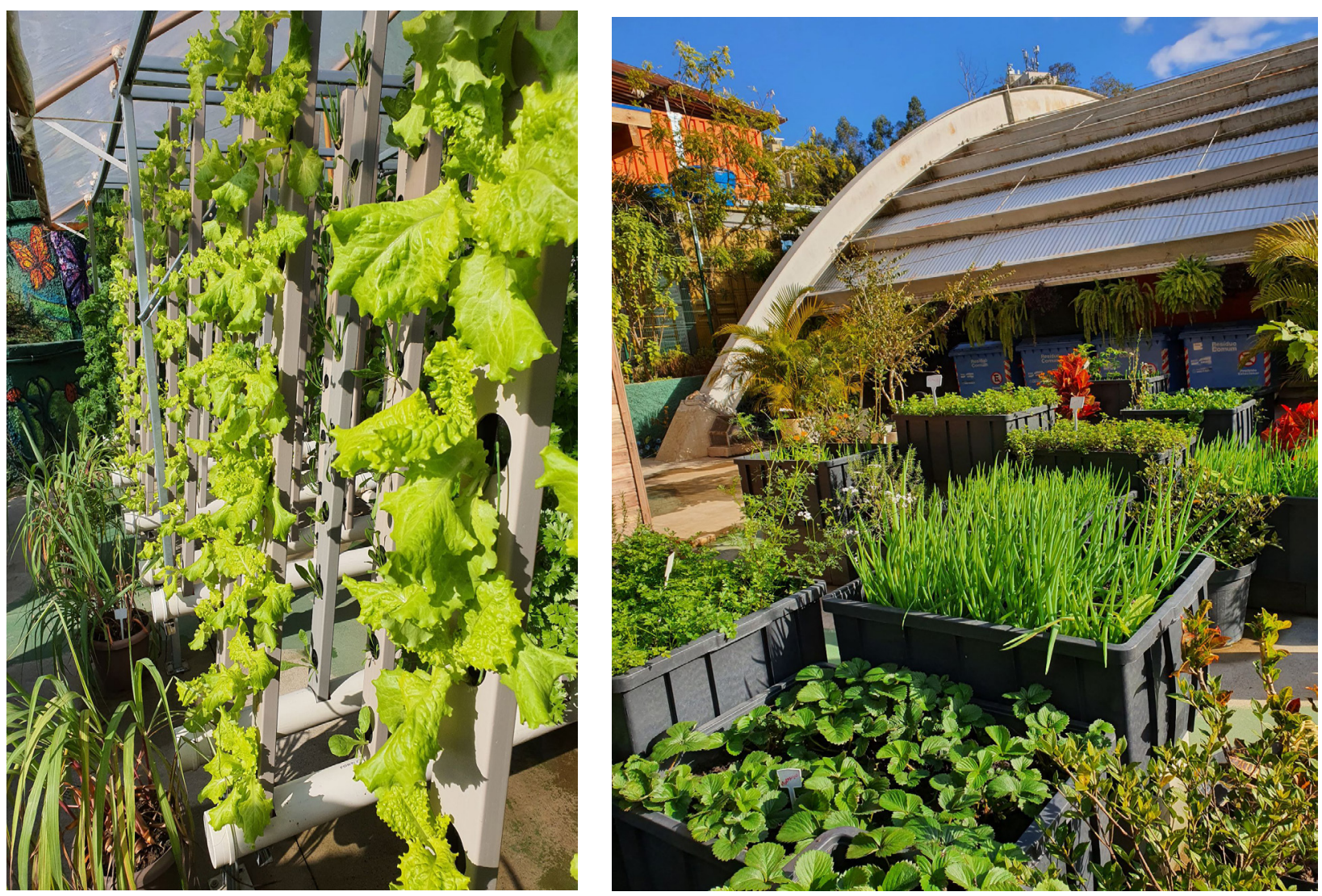

FIGURAS 3 e 4. AgroFavela-Refazenda Fonte: Acervo da autora, 2021. 
Horta Popular Criando Esperança. Vila Nova Esperança, Zona Oeste - SP

Com o intuito de entender a autogestão de uma comunidade em todo o projeto de horta comunitária, foi selecionada a Horta Popular Criando Esperança, na Vila Nova Esperança, comunidade localizada na Zona Oeste de São Paulo, na divisa com Cotia e Taboão da Serra. Seu território começou a ser ocupado no final dos anos 1960, próximo a uma reserva de Mata Atlântica adquirida pela CDHU em 2001, onde desde 2019 é o Parque Jequitibá ${ }^{5}$. Atualmente é constituída por aproximadamente 600 famílias, de acordo com a líder comunitária Lia Esperança. Com o intuito de se tornar um exemplo de comunidade sustentável a fim de evitar remoções e entraves jurídicos, a Vila Nova Esperança iniciou diversos projetos de cunho ambiental, sendo o principal a horta comunitária. Possui atualmente três composteiras, uma cozinha comunitária e a sede do Instituto Lia Esperança, equipada com uma fossa de evapotranspiração; biblioteca e um circo, palco de atividades culturais, todos feitos com bioconstrução, a partir de técnicas e materiais locais ou que seriam descartados.

A comunidade ocupava parte de uma ZEPAM, mas em 2013, através de pressão popular e após o início de projetos comunitários de baixo impacto ambiental com ampla visibilidade, o Plano Diretor foi readequado para uma ZEIS. A comunidade recebe ajuda pontual de ONGs, universitários e outros voluntários principalmente via mutirões, e já recebeu apoio de editais públicos para a viabilização dos projetos.

De acordo com a líder comunitária, a horta produz alimentos orgânicos vendidos a preço de custo para os moradores, e tem como principal objetivo garantir saúde, segurança alimentar e renda para a comunidade, além de ser um instrumento de educação ambiental para adultos e crianças tanto locais quanto externos. São plantados na horta plantas medicinais, PANCs, hortaliças, leguminosas e árvores frutíferas. Esperança (2021) destaca que "...a gente planta na horta conforme o que o povo mais pede (...) A nossa plantação é de acordo com a necessidade do povo".

Iniciada em 2013 e gerida por moradores que encontravam-se desempregados, a horta foi instalada em um terreno abandonado, e posteriormente expandiu-se para um terreno de propriedade da SABESP, através de uma parceria com a empresa. Localizada na divisa com o parque, a horta serviu também como um instrumento de

5. Anteriormente chamado de Parque Urbano de Conservação Ambiental e Lazer da Fazenda TIZO (Terras Institucionais da Zona Oeste), criado pelo Decreto Estadual n 50.597, de 27 de março de 2006. Arce et al. (2014) a caracteriza como uma área de conflito socioambiental, com disputas entre atores com interesses diversos. urbanização, limitando a expansão das casas em áreas de preservação ambiental e evitando também o despejo de entulho no local. 
nós já estamos em 2021, então isso quer dizer que ajudou a toda a comunidade, essa horta, porque o impacto dela foi muito bom. (Esperança, 2021)

Atualmente a horta é gerida por moradores desempregados em troca de cestas básicas, mas já receberam recursos de editais públicos para a remuneração do trabalho. Após diversas experimentações, incluindo a criação de uma moeda de troca para moradores da comunidade para a partilha da colheita, foi decidido que os alimentos seriam vendidos a preço de custo para moradores locais, e segundo Lia, aproximadamente dois terços dos moradores consomem da horta.

Sobre a capacitação das pessoas, a líder comunitária diz:

...eu vou te falar uma coisa: o melhor professor do mundo é
a vida. A vida já é um professor. Porque no caso eu não tenho
condição de pagar uma pessoa profissional para vir ensinar.
E aqui a gente compartilha conhecimento. Então cada um diz
"ah, eu sei isso, aprendi com o meu avô, aprendi com a minha
avó", então a gente vai compartilhando. Eu sempre falo que
aqui não tem ninguém melhor do que o outro, aqui não tem
professor. aqui todo mundo é aluno, e é aluno da natureza.
(Esperança, 2021)
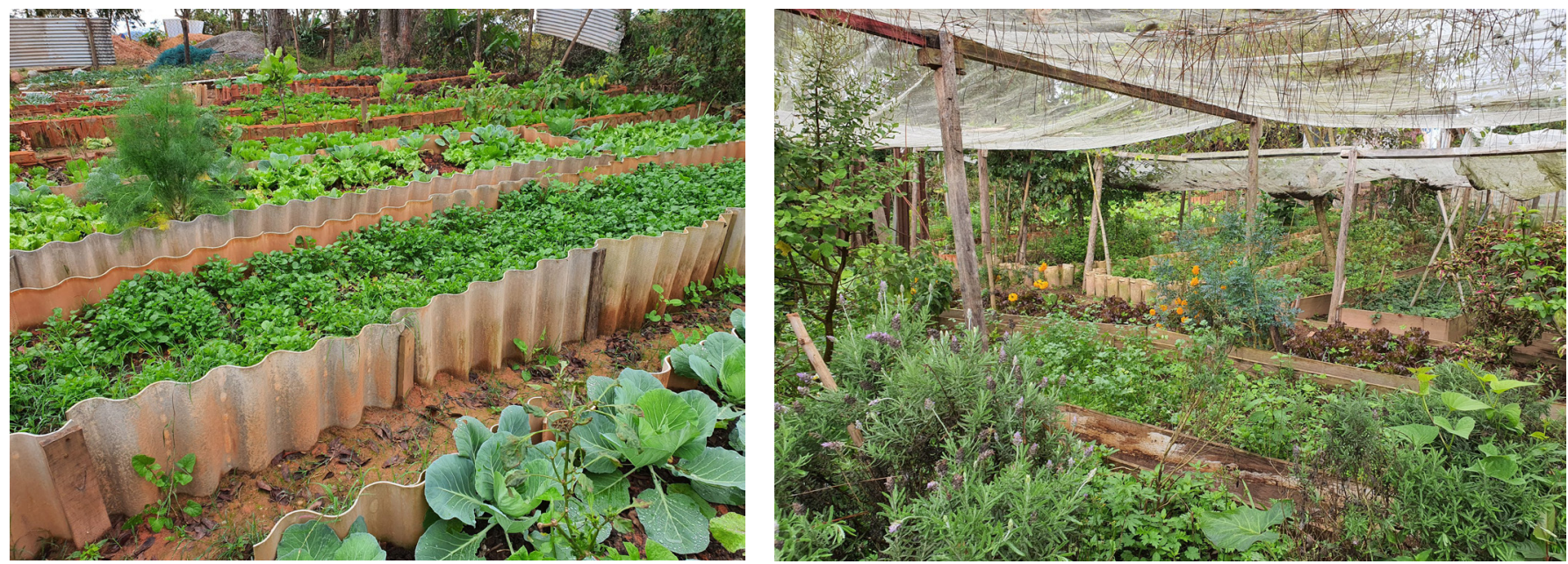

FIGURAS 5 e 6. Horta Popular Criando Esperança na Vila Nova Esperança. Fonte: Acervo da autora, 2021.

\section{RESULTADOS E DISCUSSÃO}

Considera-se neste estudo que a experiência da Vila Nova Esperança é um exemplo positivo de uma categoria de Soluções Baseadas na Natureza com envolvimento, engajamento e gestão de moradores. Trata-se de um projeto cuja idealização - da horta e outros equipamentos - partiu diretamente de uma demanda e estratégia de uma comunidade visando garantir a posse da terra, mas sem excluir a participação de ONGs e outros voluntários. A relação com estes atores foi construída como uma rede de apoio e difusão e não de dependência. Em entrevista 
com Lia Esperança, a líder comunitária, foi relatado o caso infrutífero de uma empresa que tinha interesse em investir em projetos ambientais na comunidade, mas que não consultou os moradores para entender suas demandas, realizando um diagnóstico à parte, algo diverso ao método trabalhado na Vila. Acerca da importância escuta, Esperança (2021) comenta:

Foi muito importante a gente ter essa iniciativa, mas eu acho que desde quando uma empresa, ou uma ONG, a justiça, ou qualquer um, eles virem fazer esse trabalho na comunidade, que escute o morador, que escute as pessoas, e que faça as coisas de acordo com a vontade das pessoas, e não a delas.

Em ações comunitárias, Lia comenta como a ajuda de agentes externos é bem-vinda principalmente ao instruir e popularizar informações judiciais, técnicas e educativas que são de interesse da comunidade porém de difícil acesso. Ela cita como exemplo o caso da ameaça de desapropriação, para o qual foi importante o auxílio de profissionais para explicar a situação do planejamento local, acerca da ZEIS e a ZEPAM em que estavam inseridos.

A mediação de empresas ou organizações presentes no território, quando não tecida de forma emancipatória e participativa, pode acabar por trazer instabilidade e dependência de comunidades. Como por exemplo, no caso de hortas urbanas, a necessidade de fornecimento contínuo de mudas, protótipos e insumos por meio de contratos de parceria para a continuação e manutenção dos projetos. Não são raros, em outros projetos dessa natureza, os relatos sobre ONGs e empresas que divulgam e obtém vantagens financeiras sobre suas benfeitorias ditas sociais e sustentáveis de forma desleal em cima de incertezas de comunidades que dependem de financiamentos e decisões externas pouco dialogadas e transparentes.

Ainda é cedo para afirmar que este é o caso da AgroFavela-Refazenda, em Paraisópolis, que depende de protótipos e insumos cedidos por empresas para continuarem o projeto. Assim como é precipitado avaliar o alcance e impacto da iniciativa por estar em uma fase piloto - hortas são seres vivos que requerem tempo e trabalho (a princípio local) para assegurar seu bom desenvolvimento. Embora a partilha da colheita seja feita via cadastramento das mulheres de Paraisópolis, a AgroFavela-Refazenda diferencia-se das demais hortas comunitárias de São Paulo, por não realizar a gestão do espaço de forma coletiva e colaborativa, de maneira que os moradores de Paraisópolis só participam ativamente através de oficinas de plantio, sendo a horta administrada e cuidada por uma pequena equipe.

As hortas urbanas podem ser instrumentos políticos poderosos de transformação do território, como no caso da horta da Dona Sebastiana. Na entrevista semi-estruturada realizada, Sebastiana relata que sua horta não é comunitária - segundo ela, "ser comunitária 
dá muito trabalho". Embora o projeto tenha sido assessorado por uma ONG durante 8 anos, Sebastiana ao contar sobre seus pontos de apoio destaca os funcionários da Subprefeitura de São Mateus, e a Associação de Agricultores da Zona Leste, co-fundada por seu marido. Através da Associação conseguiram criar uma rede de comercialização e divulgação, financiando cursos técnicos e consultoria de agrônomos. Além de incentivar o consumo local, a horta é também um instrumento de educação ambiental que se destaca na paisagem no bairro - de acordo com D. Sebastiana, era frequente a visita de escolas no bairro antes da pandemia do novo Coronavírus. Sebastiana conta como o terreno antes era usado para depósito de lixo e hoje é o "jardim do paraíso". É evidente a transformação social e ambiental do entorno em decorrência das hortas, não somente por reduzirem ilhas de calor, absorverem ruídos, reduzirem o risco de inundações e resguardar as nascentes locais, mas também por oferecer ao moradores do bairro o direito à paisagem (Vicente e Lima, 2017), às áreas verdes, ao lazer e, em última instância, à Justiça Ambiental.

Além do objetivo claro de geração de renda e abastecimento público de alimentos, percebe-se que as três hortas tiveram em sua criação como finalidade a ideia de propiciar educação ambiental e trazer o contato com o meio ambiente em territórios onde esse acesso é negado ou restrito. Hortas urbanas podem oferecer, através do trabalho emancipador e não alienante, experiências de reconexão não somente com áreas verdes da cidade, mas também com o passado e a ancestralidade dos trabalhadores. Este contato com as origens, combinado com a pauta da saúde mental, foi algo comentado pelas entrevistadas - quando perguntado nas três hortas onde os trabalhadores aprenderam a mexer com a terra, a resposta foi "a escola da vida" - Sebastiana e Lia, assim como Adélia, jardineira da AgroFavela-Refazenda, migraram de estados nordestinos para São Paulo no século passado, e reencontraram-se com o trabalho rural décadas depois. Na Vila Nova Esperança foi comentado como esse foi um padrão vivido por muitos de seus trabalhadores, que trocaram aprendizados e técnicas diferentes baseados em suas experiências de vida antes de mudarem-se para São Paulo, algo que teve grande impacto na saúde mental. Lia comenta como muitos moradores se curaram de depressões severas após retomarem o contato com a natureza e o trabalho rural.

Observou-se nos três projetos a presença de lideranças mulheres - por ser um local próximo de suas casas e seguro para crianças, as hortas contribuem também para a igualdade de gênero e o fortalecimento comunitário, sendo um espaço onde mulheres podem aprender novas habilidades, trocar conhecimentos e participar ativamente em decisões da comunidade. Lia Esperança comenta que atualmente a maioria dos participantes da horta são mulheres, enquanto na 
Agrofavela Refazenda as cestas da colheita e as oficinas de cultivo são direcionadas às mulheres de Paraisópolis, visando sua autonomia.

Na Vila Nova Esperança a horta configurou-se também como um mecanismo político de permanência no território que articulada com os demais projetos pautados na chave da sustentabilidade fortaleceram a luta da comunidade, ofereceram visibilidade e possibilitaram a negociação com o poder público. Quando perguntada sobre quantas pessoas se beneficiam da horta, Lia responde que dois terços da comunidade consomem da horta, mas todos os moradores são atendidos indiretamente por ela, devido à questão da posse da terra. Um outro aspecto a ser destacado é o uso da horta nessa localidade como um instrumento de urbanização, pois sua implantação foi planejada no limite do parque e áreas preservadas, impedindo a expansão do loteamento irregular nessas áreas. Onde começam a jogar lixo e entulho, ou identificam que grileiros querem ocupar e construir, a comunidade implanta jardins e áreas verdes comuns entendidas como espaços de convivência e lazer, controlando a expansão que pode ameaçar a continuidade de sua permanência.

\section{CONSIDERAÇÕES FINAIS}

Por meio da análise proposta neste artigo, constatou-se, mesmo que com níveis diferentes de impacto social e ambiental e por meio de uma única categoria, hortas urbanas, a relevância na proposição de Soluções baseadas na Natureza em comunidades periféricas de grandes centros urbanos. Estas são, em geral, vulneráveis socialmente e economicamente e as que mais sofrem de (in)justiças ambientais, por se localizarem, por exemplo, sobre terrenos contaminados e/ou sob risco de enchentes, deslizamentos, além da falta de saneamento básico e acesso à áreas verdes e de lazer.

As políticas de planejamento urbano que minimamente orientaram a organização do território da cidade de São Paulo desconsideraram a agricultura urbana como fator relevante em seu desenvolvimento, sendo esta restrita a pequenas iniciativas espontâneas realizadas em áreas abandonadas ou ainda não apropriadas pelo mercado imobiliário (Biazoti, 2020, p. 98). Gonçalves (2017) aponta que,

\footnotetext{
Uma região (tal como uma cidade ou uma comunidade) resiliente desenvolve um modelo de progresso assente em mudanças graduais e continuadas. Esse território amplia oportunidades para todos os grupos etários e sociais, estabelece e consolida uma rede de conectividades e internaliza, na sua matriz socioeconômica, condições de aprendizagem que permitem evitar ou inovar a partir de quadros de tensão. Para além disso, posiciona-se de modo a integrar sistemas territoriais que potenciem interações em
} 
múltiplas escalas. No centro das atuações, está a necessidade de facilitar uma cultura de resiliência nas esferas do estado, das organizações e dos indivíduos. (p. 383)

Incentiva-se, portanto, que projetistas, planejadores e o poder público repensem o planejamento e ocupação territorial de forma a considerar e valorizar iniciativas projetuais resilientes como resposta à injustiça ambiental e outras formas de opressão presentes nas periferias da cidade. Soluções baseadas na Natureza, quando projetadas em conjunto com comunidades e associadas ao conceito de Justiça Ambiental, podem possibilitar o pensar em outro(s) urbanismo(s) e formas de conviver com a natureza no meio urbano de forma menos desigual e mais democrática, através de práticas e equipamentos não somente mais sustentáveis, mas que envolvam também cultura, afeto e ancestralidade de populações locais. Visando a continuidade dos projetos e o envolvimento de moradores do entorno de SBNs, é interessante a participação de empresas, fundações e organizações não governamentais ocorrer em um diálogo horizontal, sem a imposição vertical de técnicas, metodologias e soluções, incentivando a autonomia dos envolvidos e proporcionando a apropriação e replicabilidade. Como último ponto, ressalta-se a importância do reconhecimento de comunidades e grupos sociais na democratização de Soluções Baseadas na Natureza, a fim de semear projetos inclusivos que vão na contramão de um urbanismo excludente, feitos por e para mais camadas da sociedade, ampliando o acesso a um meio ambiente sadio e seguro.

\section{AGRADECIMENTOS}

Aos colaboradores da pesquisa, especialmente às lideranças comunitárias e agricultoras urbanas que gentilmente cederam seu tempo, conhecimento e possibilitaram a realização de entrevistas e desta pesquisa como um todo. Aos colegas da extensão universitária da FAUUSP e do Coletivo Caetés, que contribuíram com ideias e força de vontade em projetos participativos que ainda estão por vir na Vila Nova Esperança. À Pró-Reitoria de Graduação da Universidade de São Paulo pela bolsa concedida por meio do Programa Unificado de Bolsas de Estudos para Estudantes de Graduação (PUB), Vertente Pesquisa (Edital 2020/2021). 


\section{REFERÊNCIAS}

AAZL - Associação de Agricultores da Zona Leste. (n.d.). Quem somos. Recuperado de https://agricultoreszonaleste.org.br/.

Acselrad, H., Mello, C. C. D. A. \& Bezerra, G. D. N. (2009). O que é Justiça Ambiental. 1a ed. Rio de Janeiro, RJ: Garamond.

Arce, P. A., Pendloski, C. J. S., Oliveira, R. B., Gallardo, A. L. C. F. \& Ruiz, M. S. (2014). Conflitos socioambientais em unidades de conservação em áreas urbanas: o caso do Parque Tizo em São Paulo. Revista Holos, 30 (1).

Artman, M. \& Sartison, K. (2018). The Role of Urban Agriculture as a Nature-Based Solution: A Review for Developing a Systemic Assessment Framework. Sustainability. 10(6):1937. doi:10.3390/su10061937.

Biazoti, A. R. (2020). Engajamento político na agricultura urbana: a potência de agir nas hortas comunitárias de São Paulo. Dissertação (Mestrado em Ecologia Aplicada) - Ecologia de Agroecossistemas, Universidade de São Paulo, Piracicaba. doi:10.11606/D.91.2020.tde-09032020-170856.

Bullard, R. (2005). Ética e racismo ambiental. Revista Eco 21, XV (98). Recuperado de http://www.eco21.com.br/textos/textos.asp?ID=996.

CAU/BR \& Instituto Datafolha. (2015). 2. Como o brasileiro constrói. Pesquisa CAU/ BR Datafolha. Recuperado de https://www.caubr.gov.br/pesquisa2015/como-obrasileiro-constroi/.

Cidades Sem Fome. (2021). Sobre a organização. Recuperado de https:// cidadessemfome.org/pt-br/.

Cohen-Shacham, E., Walters, G., Janzen, C. and Maginnis, S. (eds.) (2016). Naturebased Solutions to address global societal challenges. Gland, Switzerland: IUCN.

Corburn, J. (2007). Community knowledge in environmental health science: coproducing policy expertise. Environmental Science \& Policy, 10(2), 150-161.

D'andrea, T. (2020). Contribuição para a definição dos conceitos periferia e sujeitos e sujeitas periféricos. Novos Estudos - CEBRAP, 39, 19-33, jan-abr.

Esperança, L. Entrevista 2. [jun. 2021]. Entrevistador: Babette Fernandes Martins da Costa. São Paulo, 2021, 1 arquivo .mp3 (40 min.).

Fraga, R. G. \& Sayago, D. A. V. (2020). Soluções baseadas na Natureza: uma revisão sobre o conceito. Parcerias Estratégicas, 25(50), 67-82.

Gonçalves, C. (2017). Regiões, cidades e comunidades resilientes: novos princípios de desenvolvimento. Urbe. Revista Brasileira de Gestão Urbana, 9(2), 371-385.

IBGE - Instituto Brasileiro de Geografia e Estatistica. (2000). Pesquisa nacional por amostra de domicílios 1999 [CD-ROM]. Microdados. Rio de Janeiro, RJ: IBGE.

IBGE - Instituto Brasileiro de Geografia e Estatistica. (2017). IBGE propõe debate de nova classificação para os espaços rurais e urbanos. Agência IBGE Notícias. Recuperado de https://agenciadenoticias.ibge.gov.br/agencia-sala-de-imprensa/2013-agenciade-noticias/releases/15003-ibge-propoe-debate-de-nova-classificacao-para-osespacos-rurais-e-urbanos.

Laituri, M. \& Kirby, A. (1994). Finding Fairness in America's Cities? The Search for Environmental Equity in Everyday Life. Journal of Social Issues, 50(3).

LSBN - Laboratório De Soluções Baseadas Na Natureza. Laboratório da Poli-USP busca inspiração na natureza para propor soluções para construção civil. (n.d.). Site da Escola Politécnica da Universidade de São Paulo. Recuperado de https://www. poli. usp.br/noticias/48615-laboratorio-da-poli-usp-busca-inspiracao-na-natureza-parapropor-solucoes-para-construcao-civil.html. 
Maricato, E. (2015). Para entender a crise urbana. São Paulo, SP: Expressão Popular.

Martins, G. A. (2008). Estudo de caso: uma reflexão sobre a aplicabilidade em pesquisas no Brasil. RCO - Revista de Contabilidade e Organizações, FEARP/ USP, 2(2), 8-18. Recuperado de https://www.revistas.usp.br/rco/article/viewFile/34702/37440.

Noia, P. R. C. (2017). Participação e qualidade do ambiente construído na habitação: processo e produto no programa Minha Casa Minha Vida - Entidades. (Tese de Doutorado), Faculdade de Arquitetura e Urbanismo, Universidade de São Paulo, São Paulo. doi:10.11606/T.16.2017.tde-22062017-151733.

Oliveira, R. G. (2018). Práticas de saúde em contextos de vulnerabilização e negligência de doenças, sujeitos e territórios: potencialidades e contradições na atenção à saúde de pessoas em situação de rua. Saúde e Sociedade [online] , 27(1), 37-50. doi: 10.1590/ S0104-12902018170915.

Renata. Entrevista 3. [jun. 2021]. Entrevistador: Babette Fernandes Martins da Costa. São Paulo, 2021, 1 arquivo .mp3 (16 min.).

Rodrigues, L. S. (2020). Representações sociais e injustiça ambiental: o gerenciamento de riscos no Conjunto Heliópolis-Gleba L-SP. Dissertação (Mestrado em Ciência Ambiental) - Instituto de Energia e Ambiente, Universidade de São Paulo, São Paulo. doi: 10.11606/D.106.2020.tde-08092020-144140.

Rodrigues, P. N., Alcântara, V. C., Yamamoto, E. A. F. S., Campos, A. C. \& Bacelar, A. S. (2021). Aprendendo com a natureza: uma revisão sobre Nature-Based Solutions (NBS). Revista Gestão e Sustentabilidade Ambiental, 10, 417-436. Recuperado de https:// www.researchgate.net/publication/352053936_Aprendendo_com_a_natureza _ uma_revisao_sobre_Nature-Based_Solutions_NBS.

Sebastiana. Entrevista 1. [jun. 2021]. Entrevistador: Babette Fernandes Martins da Costa. São Paulo, 2021, 1 arquivo .mp3 (34 min.).

Stöberl, A. P. M., Diaz, L. T., Gadda, T. M. C. \& Vellozo, L. D. (2019). Trajetória do conceito Soluções baseadas na Natureza e a relação com o Brasil: uma análise bibliográfica. Anais. XVIII ENANPUR. Natal. Recuperado de http://anpur.org.br/ xviiienanpur/anaisadmin/capapdf. php? reqid $=1304$.

IUCN - International Union For Conservation Of Nature. (2020), Global Standard for Nature-based Solutions. A user-friendly framework for the verification, design and scaling up of NbS. 1nd ed. Gland, Switzerland: IUCN. Recuperado de https://portals. iucn.org/library/node/49070.

United States Environmental Protection Agency. (n.d.). Environmental Justice. Recuperado de https://www.epa.gov/environmentaljustice.

Universidade de São Paulo. Sistema Integrado de Bibliotecas da USP. (2016). Diretrizes para apresentação de dissertações e teses da USP: parte II (APA) (3a ed.). São Paulo, SP: SIBiUSP. Recuperado de http://www.livrosabertos.sibi.usp.br/portaldelivrosUSP/ catalog/book/112.

Vicente, P. M. \& Lima, C. P. C. S. (2017). Parque Pinheirinho d'Água: a construção coletiva do espaço público. Anais. XVII ENANPUR. São Paulo. Recuperado de http:// anpur.org.br/xviienanpur/principal/publicacoes/XVII.ENANPUR_Anais/ST_Sessoes_ Tematicas/ST\%2011/ST\%2011.2/ST\%2011.2-05.pdf.

Yin, R. K. (2001). Estudo de Caso, planejamento e métodos. (2a ed.). São Paulo, SP: Bookman. 


\section{Babette Fernandes Martins da Costa}

Graduanda e Pesquisadora de Iniciação Científica no Curso de Arquitetura e Urbanismo da FAUUSP

ORCID: https://orcid.org/0000-0002-8213-3506

babettecosta@usp.br

\section{Tatiana Sakurai}

Docente nos Cursos de Graduação em Arquitetura e Urbanismo e de Design da FAUUSP. Orientadora credenciada no Programa de Pós-Graduação em Arquitetura e Urbanismo da FAUUSP

ORCID: ORCID: https://orcid.org/0000-0001-5769-7492

tsakurai@usp.br

Recebido em: 08/08/2021.

Aceito em: 05/12/2021. 